\title{
X-sinus: geen toegevoegde waarde voor de huisarts
}

\begin{abstract}
Samenvatting
Venekamp RP, Cals JWL. X-sinus: geen toegevoegde waarde voor de huisarts. Huisarts Wet 2016;59(7):302-3

Acute rhinosinusitis is een veelvoorkomende aandoening in de huisartsenpraktijk. Ofschoon de X-sinus geen plek heeft in de NHG-Standaard Acute rhinosinusitis vragen huisartsen nog geregeld een X-sinus aan. De X-sinus heeft echter onvoldoende diagnostische waarde en is niet bruikbaar om patiënten te selecteren bij wie een antibioticum effectiever is. Daarom heeft de X-sinus geen behandelconsequenties bij patiënten met klachten die passen bij acute rhinosinusitis. Bij verdenking op acute rhinosinusitis staat de X van X-sinus dus gewoon voor 'niet doen'.
\end{abstract}

\section{INLEIDING}

In dit artikel bespreken we de waarde van de X-sinus voor de huisarts. We richten ons op het nut van de X-sinus bij het aantonen en uitsluiten van de diagnose acute rhinosinusitis en de gevolgen die deze aanvraag kan hebben voor het therapeutische beleid. Onze aanbeveling voor de dagelijkse praktijk vindt $\mathrm{u}$ in de laatste zin van dit artikel. Hieronder leest $\mathrm{u}$ hoe we tot deze conclusie komen.

Het natuurlijk beloop van een acute rhinosinusitis is over het algemeen gunstig, want circa 90\% van de patiënten is binnen drie weken klachtenvrij. Daarnaast is de incidentie van ernstige complicaties zeer laag. ${ }^{1}$ Zowel nationale als internationale richtlijnen adviseren terughoudendheid bij het voorschrijven van antibiotica bij patiënten met klinisch gediagnosticeerde acute rhinosinusitis. ${ }^{2-4}$ Hoewel Nederland wat betreft deze indicatie tot de landen met het laagste aantal antibioticumvoorschriften behoort, krijgt in ons land circa de helft van alle patiënten met een acute rhinosinusitis nog een antibioticum. 5,6 De wensen en eerdere ervaringen van de patiënt spelen hierbij mogelijk een rol, hoewel onderzoek heeft aangetoond dat bij het daadwerkelijk voorschrijven van een antibioticum de vooronderstellingen van de huisarts over de wens van de patiënt om een antibioticum te ontvangen een belangrijke rol spelen.7 Dat huisartsen bij dit ziektebeeld relatief vaak antibiotica voorschrijven komt misschien ook doordat ze merken dat bepaalde patiënten wel degelijk goed reageren op een antibioticum. Helaas heeft een meta-analyse van individuele patiëntengegevens aangetoond dat deze observatie niet wetenschappelijk onderbouwd kan worden: er is op basis van klinische gronden (inclusief lichamelijk onderzoek) geen subgroep aan te wijzen die meer baat heeft bij een antibioticum. ${ }^{8}$ Met een röntgenopname van de holten kan men mucosazwel-

UMC Utrecht, Julius Centrum voor Gezondheidswetenschappen en Eerstelijns Geneeskunde, Postbus 85500,3508 GA Utrecht: dr. R.P. Venekamp, huisarts-onderzoeker. UMC Utrecht, afdeling Keel-, Neus- en Oorheelkunde, Divisie Heelkunde: dr. R.P. Venekamp, huisarts-onderzoeker. Universiteit Maastricht, CAPHRI School for Public Health and Primary Care, vakgroep Huisartsgeneeskunde, CAPHRI School for Public Health and Primary Care: dr. J.W.L. Cals, huisarts-onderzoeker • Correspondentie: R.P.Venekamp@umcutrecht.nl • Mogelijke belangenverstrengeling: niets aangegeven. ling en sluiering van de holten zien, die kunnen wijzen op een ontsteking van de neus- en bijholten. Ofschoon de X-sinus geen plek heeft in de NHG-Standaard Acute rhinosinusitis vragen huisartsen nog geregeld een X-sinus aan. ${ }^{2}$ Zo hebben huisartsen in het adherentiegebied van een Limburgs ziekenhuis in 2013 en 2014 in totaal respectievelijk 531 en 347 maal een $\mathrm{X}$-sinus aangevraagd en bleek dit type aanvullend onderzoek in een regionaal ziekenhuis in Leiden o,8\% van het totaal door de huisarts aangevraagde radiologische onderzoeken te beslaan. De vraag is of aanvullend onderzoek, bijvoorbeeld in de vorm van een $\mathrm{X}$-sinus, een bijdrage kan leveren aan de diagnostiek én de beslissing om al dan niet een antibioticum voor te schrijven bij patiënten met klachten die passen bij een acute rhinosinusitis.

\section{DE WAARDE VAN DE X-SINUS}

\section{De diagnostische waarde}

Bij de interpretatie van een $\mathrm{X}$-sinus kan men verschillende criteria aanhouden om de diagnose acute rhinosinusitis te stellen: mucosazwelling, een vloeistofspiegel of volledige sluiering. Bij zowel een systematische review ${ }^{9}$ als een meta-analyse ${ }^{10}$ van zes onderzoeken met bijna duizend patiënten heeft men gekeken naar de relatie tussen deze bevindingen op een $\mathrm{X}$-sinus en het aspiraat dat men vond bij een sinuspunctie. Hierbij hebben de onderzoekers de aanwezigheid van slijm, pus of vocht bij de sinuspunctie als referentiestandaard voor de diagnose acute rhinosinusitis genomen. Voor de sensitiviteit en specificiteit blijkt het heel belangrijk te zijn waarnaar men op de X-sinus kijkt. Wanneer men naar een vloeistofspiegel of volledige sluiering kijkt, dan blijken de sensitiviteit en specificiteit respectievelijk 0,73 (95\%-betrouwbaarheidsinterval (BI) o,6o tot o,83) en o,8o $(95 \%$-BI o,71 tot o,87) te bedragen. Wanneer men tevens mucosazwelling waarneemt op de Xsinus en deze toevoegt aan de eerder genoemde criteria, dan bedragen de sensitiviteit en specificiteit respectievelijk o,90 $(95 \%$-BI 0,68 tot 0,97$)$ en $0,61(95 \%-B I$ o,20 tot 0,91$)$. Belangrijk hierbij is wel dat slechts twee onderzoeken in de eerste lijn plaatsvonden en dat dat juist de twee onderzoeken met de laagste sensitiviteit betrof (respectievelijk o,61 en o,63). ${ }^{11,12}$

Op grond van bovenstaande gegevens blijkt een vloeistofspiegel of volledige sluiering op de X-sinus - bij een geschatte

\section{De kern}

- Huisartsen vragen geregeld de X-sinus aan voor de diagnostiek van acute rhinosinusitis.

- De diagnostische waarde van de X-sinus is te beperkt om acute rhinosinusitis te kunnen aantonen of uitsluiten.

- De $X$-sinus is niet bruikbaar om patiënten te selecteren bij wie een antibioticum effectiever is en heeft derhalve geen behandelconsequenties. 
prevalentie van acute rhinosinusitis van $50 \%$ bij patiënten met typische klachten - de kans op acute rhinosinusitis te verhogen naar $78 \%$, terwijl een negatieve $\mathrm{X}$-sinus de kans naar $25 \%$ verlaagt. ${ }^{10}$ Daarnaast is het de vraag of het aspiraat bij sinuspunctie wel de beste referentiestandaard is, want mogelijk zorgt deze definitie voor een overschatting van het aantal bacteriële acute rhinosinusitiden, en de daarmee gepaard gaande testeigenschappen van de X-sinus. De testeigenschappen van een X-sinus zijn dus onvoldoende om de aan- of afwezigheid van een acute bacteriële rhinosinusitis te voorspellen.

\section{Behandelconsequenties}

Betere diagnostiek is alleen relevant als we daardoor de behandeling en dus de prognose van het ziektebeeld (voordelig) kunnen beïnvloeden. Kunnen afwijkingen op de X-sinus bijdragen aan het aanwijzen van een subgroep van patiënten met klachten die passen bij een acute rhinosinusitis en die meer baat hebben bij een antibioticum? Een dubbelblind, placebogecontroleerd gerandomiseerd onderzoek heeft deze hypothese getoetst in Nederlandse huisartsenpraktijken bij 214 patiënten met afwijkingen op de X-sinus. ${ }^{13} \mathrm{Na}$ twee weken bleek het percentage patiënten bij wie de klachten substantieel verbeterd of verdwenen waren in de groep die een behandeling kreeg met amoxicilline $750 \mathrm{mg}$ driemaal daags niet te verschillen met dat in de groep die een placebo kreeg (respectievelijk 83\% versus 77\%). De X-sinus draagt bij patiënten met klachten die passen bij een acute rhinosinusitis dus niet bij aan het selecteren van een groep patiënten die meer baat hebben bij antibiotica.

\section{BESCHOUWING}

Op basis van anamnese, lichamelijk onderzoek en X-sinus kunnen we bij patiënten met klachten die passen bij een acute rhinosinusitis tot op heden geen subgroep aanwijzen die meer dan andere patiënten baat heeft bij behandeling met een antibioticum. Een Noors onderzoek uit 1996 heeft aangetoond dat behandeling met antibiotica veel effectiever was dan een placebo bij patiënten met klachten die passen bij een acute rhinosinusitis én met een vloeistofspiegel of complete sluiering op de CT-scan. ${ }^{14}$ Een goede verklaring voor deze opvallende bevinding ontbreekt en men heeft tot op heden nooit vervolgonderzoek gedaan dat de resultaten bevestigd (of ontkracht). Bovendien wegen eventuele voordelen van het routinematig verrichten van een CT-scan bij patiënten met klinisch gediagnosticeerde acute rhinosinusitis niet op tegen de nadelen (zoals kosten- en stralenbelasting). Andere zinvolle aanvullende diagnostische tests zijn er tot op heden niet. Daarmee blijft rhinosinusitis gewoon een diagnose op basis van anamnese en beperkt lichamelijk onderzoek.

\section{CONCLUSIE}

De X-sinus heeft onvoldoende diagnostische waarde en heeft geen behandelconsequenties bij patiënten met klachten die passen bij acute rhinosinusitis. Bij vermoeden van acute rhinosinusitis staat de X van X-sinus dus gewoon voor 'niet doen'.
Dit artikel maakt onderdeel uit van de serie 'Zinnig en zuinig: kritisch over diagnostiek'.

\section{LITERATUUR}

1 Hansen FS, Hoffmans R, Georgalaz C, Fokkens WJ. Complications of acute rhinosinusitis in the Netherlands. Fam Pract 2012;29:147-53.

2 Venekamp RP, De Sutter A, Sachs A, Bons SCS, Wiersma Tj, De Jongh E. NHG-Standaard Acute rhinosinusitis. www.nhg.org.

3 Rosenfeld RM, Piccirillo JF, Chandrasekhar SS, Brook I, Ashok Kumar K, Kramper M, et al. Clinical practice guideline (update): adult sinusitis. Otolaryngol Head Neck Surg 2015;152:S1-S39.

4 National Institute for Health and Care Excellence. Respiratory tract infec tions: prescribing of antibiotics for self-limiting respiratory tract infections in adults and children in primary care, 2008. https://www.nice.org.uk/ guidance/cg69/resources/guidance-respiratory-tract-infections-antibiotic-prescribing-pdf.

5 Venekamp RP, Rovers MM, Verheij TJ, Bonten MJ, Sachs AP. Treatment of acute rhinosinusitis: discrepancy between guideline recommendations and clinical practice. Fam Pract 2012;29:706-12.

6 Van den Broek d'Obrenan J, Verheij TJ, Numans ME, Van der Velden AW. Antibiotic use in Dutch primary care: relation between diagnosis, consultation and treatment. J Antimicrob Chemotherap 2014;69:1701-7.

7 Akkerman AE, Kuyvenhoven MM, Van der Wouden JC, Verheij TJ. Determinants of antibiotic overprescribing in respiratory tract infections in general practice. J Antimicrob Chemother 2005;56:930-6.

8 Young J, De Sutter A, Merenstein D, Van Essen CA, Kaiser L, Varonen H, et al. Antibiotics for adults with clinically diagnosed acute rhinosinusitis: a meta-analysis of individual patient data. Lancet 2008;371:908-14.

9 Varonen H, Makela M, Savolainen S, Laara E, Hilden J. Comparison of ultrasound, radiography, and clinical examination in the diagnosis of acute maxillary sinusitis: a systematic review. J Clin Epidemiol 2000;53:940-8.

10 Engels EA, Terrin N, Barza M, Lau J. Meta-analysis of diagnostic tests for acute sinusitis. J Clin Epidemiol 2000;53:852-62.

11 Laine K, Määttä T, Varonen H, Mäkelä M. Diagnostic acute maxillary sinusitis in primary care: a comparison of ultrasound, clinical examination and radiography. Rhinology 1998;36:2-6.

12 Van Buchem L, Peeters M, Beaumont J, Knottnerus JA. Acute maxillary sinusitis in general practice: the relation between clinical picture and objective findings. Eur J Cen Pract 1995;1:155-60.

13 Van Buchem FL, Knottnerus JA, Schrijnemaekers VJJ, Peeters MF. Primary-care-based randomised placebo-controlled trial of antibiotic treatment in acute maxillary sinusitis. Lancet 1997:349:683-7.

14 Lindbaek M, Hjortdahl P, Johnsen UL. Randomised, double blind, placebo controlled trial of penicillin $V$ and amoxycillin in treatment of acute sinus infections in adults. BMJ 1996;313:325-9.

\section{Abstract}

Venekamp RP, Cals JWL. Sinus X-ray is not of value to general practitioners. Huisarts Wet 2016;59(7):302-3.

Acute rhinosinusitis is a common disorder in general practice. Although sinus X-ray has not been included in the NHG (Dutch College of General Practitioners) guideline 'Acute rhinosinusitis', general practitioners often order this investigation. However, sinus X-ray is of limited diagnostic value and is not useful for determining in which patients antibiotics will be effective. As findings have no consequences for the treatment of patients with symptoms of acute rhinosinusitis, the investigation should not be ordered when this condition is suspected. 